\title{
Study on the relationship between external Learning and Radical Innovation
}

\author{
Liwei Wang \\ International Business School \\ Yunnan University of Finance and Economics \\ Kunming, China \\ 1273553993@qq.com
}

\author{
Ying Yang* \\ International Business School \\ Yunnan University of Finance and Economics \\ Kunming, China \\ 11476423@qq.com
}

\begin{abstract}
Chinese enterprises are facing a highly dynamic and uncertain competitive market environment, and under the influence of external environment, the failure rate of independent Based on the situation of poor breakthrough innovation faced by Chinese high-tech enterprises, this paper divides the external learning sources of enterprises into government, suppliers, customers, competitors and scientific research institutions. And from these 5 dimensions, we make an empirical analysis of radical technological innovation and radical management innovation of enterprises. Through data analysis, it can be found that external learning has positive effect on radical technological innovation of enterprises, and external learning has positive effect on radical management innovation of enterprises.
\end{abstract}

On the basis of the research results, this paper puts forward the following suggestions: 1) Enterprises should strengthen the relationship construction with the government, pay close attention to the government to make and modify the market laws and regulations. 2) Enterprises should establish good cooperative relationship with suppliers, attach importance to the management strategies of suppliers, and put forward corresponding countermeasures. 3) Enterprises should strengthen the contact with scientific research institutions and automobiles. The enterprises should pay close attention to the management mode of the competitors, understand the development trend of the competitors, and carry out reasonable competition. 4)Enterprises should pay close attention to the management mode of the competitors, understand the development trend of the competitors, and make a reasonable analysis of the competitors. 5)Enterprises should pay close attention to the management mode of competitors, understand the development trend of competitors, and make reasonable analysis of competitors. The management behavior of competitors can enhance the management innovation ability of enterprises.

Keywords—external learning; radical innovation

\section{INTRODUCTION}

\section{A. Research Background}

Since entering the 21 st century, enterprises are facing a highly dynamic and uncertain competitive environment. The strategic planning, which is dominated by the internal knowledge structure and the inherent technological process, reduces the ability of the enterprise to cope with the turbulent external environment, also makes the enterprise's innovation ability cannot be further developed. Continuous successful research, development and introduction of new products is the only way to achieve enterprise innovation and improve enterprise performance. However, the failure rate of product development is quite high: only one out of every seven new product ideas can be succeed. Therefore, based on the above problems, this paper takes the source of external learning as the research object, and then divides it into five dimensions; and explains the different sources of external education, what enterprises should learn, how to learn, and maximize the efficiency of their radical innovation. Therefore, based on this purpose, combined with the specific data, this paper puts forward some guiding suggestions to reduce the risk of radical innovation in enterprises, so as to enhance the radical innovation of enterprises.

\section{B. The Meaning and Classification of External Learning}

\section{1) The meaning of external learning}

Sinkula thought external learning in an organization was originally referred to as an organization learning from an external market [1]; Schroeder et al. to further express external learning as a cross-organizational learning between an enterprise and a supplier, a customer, through joint problem-solving and long-term relationships [2]. Weerawardena proposed that it is primarily about learning from the market, including learning about the needs of customers and dynamic behaviour of competitors [3]; Fu Hui and $\mathrm{Fu}$ Bing proposed that external learning is a series of activities to organize the absorption, digestion, utilization and reconstruction of knowledge through suppliers, customers, competitors and other types of collaborators [4]; based on the above exposition of external learning, Considering the current market environment of enterprises, the government as one of the enterprises to acquire knowledge, its role is increasingly prominent, so this paper defines external learning as follows: organizations through the government, suppliers, Customers and others in the same industry provide heterogeneous sources for the renewal and creation of organizational information, and a series of activity processes through absorption, analysis, transformation and re-creation.

*Corresponding author 


\section{2) The classification of external learning}

External learning, as its name implies, begins with a series of new ideas acquired from the outside. These new ideas come from many sources: 1) In many industries, consumer feedback is the most common new source of information. This is especially true for mainstream consumers, who often offer valuable advice; 2) many improvements of product and process come from imitation of the same industry. Many companies now collect information by testing competitors' patents, marketing products, public acceptance, and using sophisticated competitor analysis systems. In addition, some reverse engineering and other organizations can also produce new products out of competitors. Process upgrading may be the best practice of benchmarking firms in the industry; 3 ) many organizations learn from other industries, such as supporting industries, universities, and government research centers. Therefore, according to the actual market environment of Chinese enterprises, this paper classifies the sources of external knowledge acquisition as follows:

Organization to learn from the Government. Politics and management are important factors in the external environment of the organization. The government plays an important role in the process of economic and social development and affects the development and operation of the organization. Compared with developed economies, it is more difficult and risky to carry out radical innovation under the current economic background of our country. Han Chen and Gao Shanxing [5] proposed that although the research on breakthrough innovation is booming, the practice of breakthrough innovation in our country is not optimistic: most enterprises are facing the shortage of their own innovation resources, and the government is the ultimate controller of the scarce resources. Therefore, from the government agencies, actively communicate with the government, understand the direction of government policies and related industrial development laws and regulations, and strengthen the ability of organizational breakthrough innovation from this level.

Organizational learning from suppliers. Organizational learning from suppliers refers to enterprises learning from other enterprises in their supply chain. Organizations learn from suppliers, mainly by transforming supplier capabilities (such as innovation capabilities) into resources needed by enterprises, such as obtaining high-quality raw materials, reducing production costs, and improving product quality. To provide better service and speed up the production of products.

Organizations learn from customers. Today, many organizations have changed from commodity-oriented to customer-oriented. Customers are critical to organizational development. $20 \%$ of customers can generate $80 \%$ of profits. For every $5 \%$ drop in customer turnover, profits can increase $100 \%$. Therefore, organizations must learn from customers to understand customers' needs, tastes and purchase preferences to enhance customer satisfaction and loyalty. Learning from customer feedback, the organization can identify its own problems and advantages, improve service and management, and promote product innovation. The organization learns from customer survey reports to obtain market information, market trends, and other knowledge that helps to improve products to meet market's requirement.

Organization to learn from competitors. In a dynamic environment, organizations must understand and learn from their peers. The adoption of dynamic competitive strategy is an important way for an organization to maintain its competitive advantage. The theory of dynamic competition is the research result of the competition behavior among companies. Smith K G and Grimm C M believed that in order to gain the competitive advantage in the market, enterprises will launch a competition attack on other competitors [6]. And this behavior will cause other competitive enterprises to counterattack and resist the dynamic competition among enterprises. The purpose of this behavior is not only to attack, but also to achieve social results that are beneficial to the enterprise itself and its employees through the interactive process of counterattack. Through cooperation with competitors or competition to achieve win-win. In the interaction with competitors, enterprises can develop science and technology or establish industry standards, and competitors may even bring new challenges and ideas to enterprises, thus making them aware of new opportunities. Enterprises can also through competing or cooperating to mimic competitors to improve the organization's innovation ability.

Learning from scientific research institutions. In 1992, in order to strengthen the cooperative relationship between universities and enterprises, mobilize the enthusiasm of industrial and academic cooperation, and accelerate the industrialization of high-tech achievements in China, the former State Economic and Trade Commission, the Ministry of Education, and the Chinese Academy of Sciences were the leading institutions. The joint development project between industry, university and research has been organized and implemented nationwide. Its goal is to promote a group of large and medium-sized enterprises to establish a stable and close cooperative relationship with universities and institutes affiliated to the Chinese Academy of Sciences, to promote the exchange of scientific research personnel, and to jointly establish technological development institutions of enterprises through cooperation.

Nowadays, the international competition is the competition of comprehensive strength. From the development experience of advanced countries, the economic development driven by scientific and technological innovation is sustainable. In order to gain the advantage in the market competition, the enterprise must base on the advanced technical ability, the market demand and the competition are the main motive force for the enterprise to carry on the technical innovation. Based on the theory of enterprise resources, the internal resources of enterprises are limited under the market conditions, and the internal integration and development of resources can not meet the needs of enterprises for technological innovation and upgrading. Therefore, enterprises must strengthen their learning from scientific research institutions in order to acquire new technologies and enhance their own technological capabilities, thus enhancing their market competitiveness. 


\section{Related Theories of Radical Innovation}

\section{1) The meaning of radical innovation}

The focus on radical innovation can be traced back to Schumpeter, the founder of innovation theory, who points out that "the long-term fluctuations in the process of technological change and creative destruction caused by new technologies and new skills create or redefine enterprises and existing markets." This definition defines the fundamental characteristics of radical innovation. With the deepening of radical innovation, scholars at home and abroad have given the definition of breakthrough innovation from different angles: Zhou, Yim [7] describes breakthrough innovation as the addition of new, unique or advanced technological improvements to a product that can significantly influence the consumption patterns of the market. Ji Dan, Guo Zheng [8] points out that radical innovation can be technological innovation, business model innovation, product innovation. Technological innovation appears in a certain form, giving customers the feeling of excess value. It is a kind of extraordinary competition mode, which can impact on the status of existing enterprises and promote industrial progress. "Radical innovation" refers to the first time that enterprises put new products or new technologies into the new market, and it is a radical change with revolutionary changes.

By summing up the above views, we can see that the definition of radical innovation is mainly from two perspectives, one is a breakthrough at the technical level, the other is a breakthrough at the business model level. We give the concept of radical innovation: radical innovation is based on a different set of scientific and technological principles that aim to create new markets and products through changes in products, processes, or services. An innovative act of changing market rules and competition.

\section{2) Classification of radical innovation}

From the definition point of view, understanding radical innovation can be seen from two angles, from the perspective of the impact of radical innovation on the external market, radical innovation refers to innovation at the level of technology and products, and from the perspective of the impact of radical innovation on the enterprise itself, radical innovation refers to radical management innovation.

Radical technological innovation. The emergence of radical innovative products usually leads to a great leap forward in the main indicators of product performance (including greatly reducing costs, improving the technical performance of products, etc.), thus withdrawing enterprises that do not adopt new technologies from the market. And destroy old industries (such as video tubes replaced by plasma, or even dramatic changes that revolutionize the entire industry. Generally speaking, radical innovation mainly through the following three aspects of breakthrough: 1) products and services. The innovation we most understand is the innovation of existing products and technologies, or the introduction of new products, because customers can immediately see the changes made to the. 2) process technology: Innovating the production and delivery of products and services, and get better, faster and cheaper products and services. Innovations in these processes are often invisible to customers, but are essential to the competitiveness of the product. Using the existing technology without changing the product or process can help the enterprise to implement the strategy more quickly and thus gain a competitive advantage in terms of time.

Radical management innovation. Radical management innovation mainly refers to the enterprise through the study of other enterprises management model and business development model and combined with the characteristics and development needs of the enterprise to develop a set of management system and business operation model suitable for this enterprise.

\section{3) Characteristics of radical innovation}

Compared with incremental innovation, radical innovation is a kind of non-sustainable innovation, which has remarkable characteristics. This paper comprehensively analyzes the characteristics of radical innovation in terms of its essence and influencing factors:

Uncertainty. Radical innovation is an extraordinary innovation activity in the face of constantly changing resource environment and consumer demand on a new track. Enterprises can not easily master market tacit knowledge information. It is hard to find a shortcut to working with the members of the innovation network, and uncertainty in the innovation process poses a huge risk.

Revolutionary. Radical innovation is a revolution to the reality and a negation of the traditional management inertia. It breaks the traditional management mode and has a subversive effect on the industry and the economic situation. Radical innovation is a new technology that is built on a new technological track, not for the mass market, but for potential demand in non-mainstream markets, although priori knowledge is a great help to radical innovation. Radical innovation is a revolution in progressive technology. Although breakthrough technology goes through the low-end entry route and is not favored by consumers during the period of technology introduction, once the breakthrough technology is adjusted to the right track, the technological superiority will be brought into play. Assembly efficiency increases by at least 5-10 times, and the technology becomes revolutionary.

Jumping property. Innovation is chaotic, dynamic and variable, and that innovation processes are not sequential, or orderly, but nonlinear and disorderly. The innovation process is uncertain and can occur in multiple variable arenas. The radical innovation is based on a new knowledge base, taking a completely different technology path, so that the original technology development path is interrupted, so it has discontinuity characteristics. Therefore, in the development and research of new technologies and new products, there is often a process of qualitative change caused by quantitative change. 


\section{MAKE ASSUMPTIONS}

\section{A. The Relationship Between External Learning Sources and Radical Innovation}

Change D $\mathrm{R}$ and $\mathrm{Cho} \mathrm{H}$ and Lichtenthaler $\mathrm{U}$ proposed that external learning can promote the diversification of enterprise knowledge resources, and speed up the pace of enterprise radical innovation, also learning heterogeneous technical knowledge from other firms can create opportunities for firms to integrate complementary enterprise resources [9][10]. By learning successful management practices from other enterprises, enterprises can identify and compare their own management systems and concepts. Dissatisfaction with the present situation will prompt the enterprise to seek knowledge resources from outside and complete the process of "refreshing" or even "formatting". Therefore, the enterprise can re-examine the market environment and change the management concept, thus laying a foundation for the establishment of a new governance mechanism and thinking mode for the enterprise to break through innovation. While businesses can legitimize organizational change through an institutionalized process of "delegation", existing management systems and mechanisms are designed for existing products, services and organizational relationships. The disharmony between the innovation goal and the organization management restricts the enterprise radical innovation fundamentally. Therefore, through external management learning, the ability of "organizational forgetting" of innovative enterprises is enhanced, which can better deal with innovation resistance and effectively legalize organizational change. External learning has created favorable conditions for meeting the above requirements of enterprise breakthrough innovation. Based on this, this paper puts forward the following propositions:

H1: External Learning plays a positive role in Enterprise radical technology innovation;

$\mathrm{H} 2$ : External learning plays a positive role in enterprise radical management innovation;

\section{VARIABLE MEASURE AND RESEARCH METHOD}

\section{A. Research Design}

In order to solve the problem, we collect data by means of deep interview and questionnaire survey. The design of

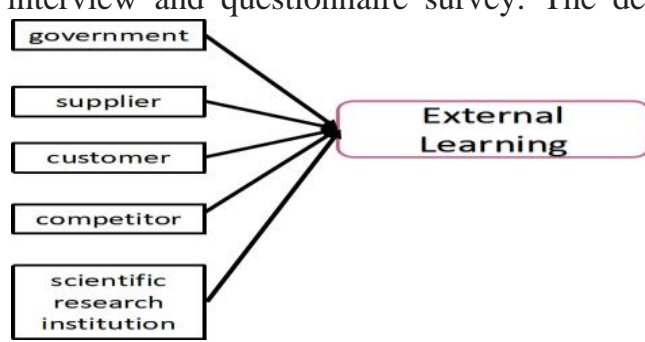

variables, design the initial questionnaire; The contents and forms of the questionnaire have been revised many times by using the brainstorming method and the advice and suggestion method of individual experts and scholars, and the managers of the three enterprises selected at random have been investigated on a trial basis, and the questionnaire has been distributed. On the basis of reliability and validity test, the contents of variable items were adjusted according to the results of the test and feedback to form a formal questionnaire. According to the purpose of the research and the need of the model hypothesis, this paper mainly uses SPSS 19.0 analysis software to analyze the survey data. Data analysis includes two parts: one is reliability and validity test, the other is reliability analysis and correlation analysis.

\section{B. Variable Measure}

All variable items were measured with the seven-point Richter scale: 1-very unsatisfactory; 7-very satisfactory.

In view of the actual market environment of Chinese enterprises, and on the basis of previous research results and actual research, according to the research object of this paper, the paper establishes five dimensions of external learning sources, namely, government, scientific research institutions, suppliers, competitors and customers. The corresponding measure index system is designed.

"Learning from Government" emphasizes the sensitivity of enterprises to the formulation and revision of relevant market laws and regulations, and the degree of close contact with the Government. Learning from scientific institutions focuses on the speed of research and development of new technologies, new methods, and new processes. "learning from suppliers" pays close attention to transform the raw materials provided by suppliers into the resources needed by enterprises, so as to reduce the cost of production and improve the quality of products. "Learning from competitor" takes into account the level of awareness of the development of competitors. "Learning from consumers" focuses on the extent to which businesses understand the constantly changing of consumers' requirements.

\section{Reliability and Validity of Variables}

In terms of reliability, ais used to test the reliability of each variable. Results (Table 1) showed that the coefficient of all

Fig. 1. The relationship between external learning and radical innovation

questionnaire and the quality of data collection are directly related to the reliability of the study. The formation process of the questionnaire can be divided into the following stages: according to the literature review to define and operate the variables was greater than 0.8 , indicating that the scale had high reliability. In terms of validity, as shown in

In Table 2, the KMO value of external learning is 0.749 , and the value of breakthrough innovation is 0.713 , indicating 
that the relevant data in this table can be used for factor analysis, and exploratory factor analysis is used to test the aggregation validity of each factor. The results are as shown in Table 3. The factor load values of all items were greater than 0.7 , and the scale had high reliability and validity.

TABLEI TABLE 1

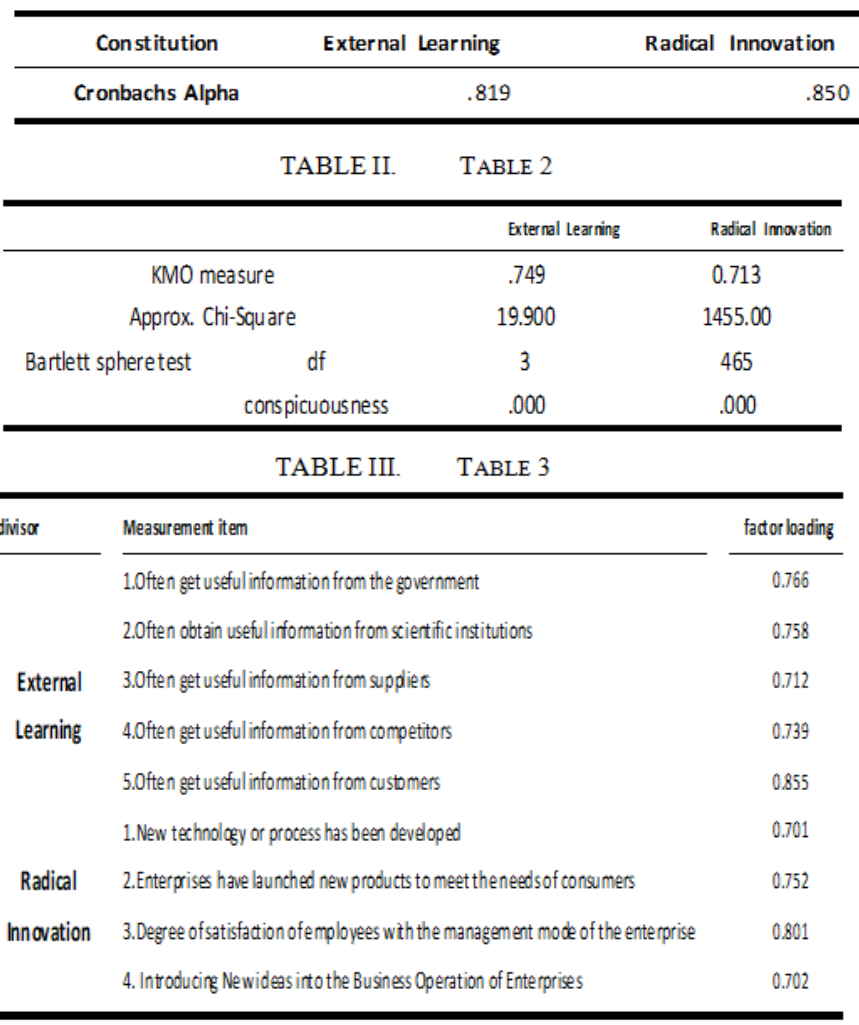

\section{Data analysis}

The main variables involved in this study are the sources of external learning (government, scientific research institutions, suppliers, competitors, customers) and radical innovation). The data analysis is shown in Table 4. Table 4 shows that the sources of external learning (government, research institutions, suppliers, competitors, customers) and radical technology innovation, There is a significant positive correlation between radical management innovation (PS < 0.01 ), indicating that there is a high correlation between independent variables and dependent variables.

\section{CONCLUSIONS AND SUGGESTIONS}

This paper studies the relationship between external learning and radical innovation, and draws the following conclusions:

(1) External learning plays a positive role in the radical technological innovation of enterprises;

(2) External learning has a positive effect on the radical management innovation of enterprises;

On the basis of combing the relevant literature at home and abroad, this paper discusses the relationship between organizational external learning and radical innovation by using empirical research methods, and then strengthens the understanding of the mechanism of knowledge transformation from external learning to radical innovation. At the same time, this study also provides theoretical guidance for enterprises to improve their radical innovation ability, and provides reliable advice for the acquisition of knowledge sources. Based on the results of the current study, the following recommendations are made in this paper:1) the enterprise should strengthen the establishment of the relationship with the government, and pay close attention to the formulation and modification of the market laws and regulations by the government; 2) the enterprise should establish a good cooperative relationship with the supplier and pay attention to the operation strategy of the supplier, so as to put forward the relevant countermeasures; 3) the enterprise should strengthen the contact with the scientific research institution and carry out the cooperation project with the scientific research institution so as to enhance the innovation ability of the enterprise; 4) the

TABLE 4

\begin{tabular}{|c|c|c|c|c|c|c|c|}
\hline Pearson & government & supplier & $\begin{array}{l}\text { scient if ic research } \\
\text { institution }\end{array}$ & competitor & customer & $\begin{array}{l}\text { technical } \\
\text { innovation }\end{array}$ & $\begin{array}{l}\text { Management } \\
\text { innovation }\end{array}$ \\
\hline
\end{tabular}

government

supplier $\quad .602 * * \quad 1$

scientific

$\begin{array}{llll}\text { research } & .804 * * & .652^{* *} & 1\end{array}$

institution

competitor

$.683 * *$

$.497 * *$

$.527 * *$

customer

$.329 * *$

$.378 * *$

$.224 * *$

$-.253 * *$

technical

innovation

$.774 * *$

$.673 * *$

$.844 * *$

$-.191 *$

$.670 * *$

1

Management

$.261 * *$

$.219 * *$

$.228 * *$

.598**

$.547 * *$

$.051 * *$

1

innovation

innovation (technological innovation, management enterprise should pay close attention to the management mode

innovation (technological innovation, management enterprise should pay close attention to the management mode 
of the competitor, understand the development trend of the competitor, and carry on the reasonable analysis to the competitor's business behavior, so as to enhance the management innovation ability of the enterprise; 5) the enterprise should pay close attention to the management mode of the competitor, understand the development trend of the competitor, and carry on the reasonable analysis to the competitor's business behavior, so as to enhance the management innovation ability of the enterprise.

\section{ACKNOWLEDGEMENT}

Firstly, I would like to extend my sincere gratitude to my tutor, for her instructive advice and useful suggestions on my paper. I am deeply grateful for her help in the completion of this paper. Without her consistent and illuminating instruction, I can't make it successfully. Secondly, I would like to thank deeply all the other teachers and classmates in Management Studies for their direct and indirect guidance and help to me.

\section{REFERENCE}

[1] J.M. Sinkula, J.M.,’Market information processing and organizational learning, Journal of Marketing”, 1994, 58(1):35-45.
[2] R.G. Schorder ,K.A. Btes, M.A. Junttila. A resourced-based view of manufacturing strategy and the relationship to manufacturing performance, Strategic Management Journal, 23, 105-117, 2002.

[3] J. Weerawardena, "Exploring the role of market learning capability in competitive strategy", European Journal of Marketing, 2007, 37 (3/4) 407-429.

[4] Fu Hui, Fu Bing "Learning ability and Enterprise performance: is knowledge Resource an intermediary variable?",Nankai Management Review, 2007, 10:23-28.

[5] Han Chen, Gao Shanxing, Political strategy, breakthrough innovation and government innovation support _ technological capabilities and strategic flexible regulatory effects : $\bar{J}$ Sustainability . Contemporary economic management ,2018, Vol.40, pp295-313.

[6] K.G. Smith, C.M. Grimm, M.J. Gannon. Dynamics of Competitive Strategy [M]. Newbury Parl, CA: Sage Publication, 1992.

[7] K.Z. Zhou, C.K. Yim, D.K. Tse, "The effects of strategic orientation on technology and market based breakthrough innovations “Journal of Marketing, 2005, 69(2):42-60.

[8] Ji Dan, Guo Zheng,'Destructive Innovation: concept, comparison and Identification", Economics and Management, 2009, 23(5): 16- 20.

[9] D.R. Change, H. Cho, "Organizational memory influences new product success", Journal of Business Research, 2008. 61(1):13-23.

[10] U. Lichtenthaler, "Organization for external technology exploitation in diversified firms", Journal of Business Research, 2010. 63(11):12451253. 